\title{
Applying Fuzzy Synthetic Evaluation Approach to Risk Assessment of Large-scale Activities
}

\author{
Zheng Jianhu $^{1,2}$ and Huang Mingfang ${ }^{1}$ \\ ${ }^{1}$ School of Economics and Management, Minjiang University, Fuzhou Fujian \\ 350108, PR China \\ ${ }^{2}$ Institute of Internet Innovation of Minjiang University, Fuzhou Fujian 350108, \\ PR China \\ E-mail:zjianhu1028@163.com
}

\begin{abstract}
Because of the complex and massive risk factors of a large-scale activity, it is difficult to assess the risk level for such activities with an accurate numerical value. Therefore, a fuzzy linguistic based approach was proposed to evaluate the risk level of large-scale activities. Taking Jay Chou's concert in 2016 as a case study, a hierarchy structure for risk assessment index system was built from the interviews with experts and literatures, which contain 14 risk factors in 4 groups. A five-point scale linguistic term was designed for the experts to evaluate the risk level of risk factors, and a fuzzy synthetic assessment model was adopted to present the procedures of risk assessment. The results reveal that the top risk factor is "safety education" and the top risk group is "management", and the overall risk criticality $(R C)$ is considered as middle. Based on the rank of $R C$ both for risk factors and risk groups, some risk management strategies were suggested.
\end{abstract}

Keywords: risk assessment, large-scale activities, fuzzy linguistic, fuzzy synthetic assessment model, risk management

\section{Introduction}

With the development of social economy and the improvement of people's life, more and more people like to participate in various large-scale activities. However, there are many potential risks in public places with massive people, as a result of increasing crowd stampede accidents. According to the public reporting both at home and broad, there were many stampede accidents happened in large-scale activities, which lead to serious casualties. Some of stampede accidents since 2010 around the world were shown in table 1. Stampede accidents once occurred in public places, not only caused a large number of casualties, but also resulted in a series of negative social impacts [1].

Table 1. Stampede Accidents of Large-scale Activities around the World

\begin{tabular}{lllll}
\hline Year & Spot & Activity type & Number of deaths & Number of injury \\
\hline 2010 & Duisburg & Love Parade & 19 & 342 \\
2011 & Cambodia & Water festival & 399 & 755 \\
2013 & India & Nine Nights & More than 115 & More than 100 \\
2014 & Shanghai & New year's activity & 36 & 49 \\
2014 & Conakry & concert & At least 34 & dozens of people \\
2015 & Mecca & pilgrimage & More than 1300 & More than 2000 \\
\hline
\end{tabular}

Large-scale activities are inevitably plagued with massive and complex risks. Some scholars made intensive research on the causes of crowded stampede accidents with regarding to large-scale activities, and put forward some general solutions for such 
accidents [2-3]. In the field of stamped accidents, foreign researches mainly concentrated on the crowded dynamics [4-6]. However, domestic researches mainly focused on the social management and risk assessment. Li Jianfeng et. al., [7] analyzed the influence of risk factors of crowded stampeded accidents, and gave some solutions for such accidents. Zhang Qingsong et. al., [8] put forward a quantitative model to analyze evacuation behaviors of stranded people in the sports field. Liu Yan et. al., [9] adopted data envelopment analysis method to assess the risk of tramped accidents in subway stations. Zhida Jiao et. al., [10] used DEA method to evaluate the risk level of crowd tramping accident in rail transit station. Li Menglong et. al., [1] established a risk assessment system with hierarchy structure, and employed analytic hierarchy process and fuzzy comprehensive method to evaluate the risk level of crowded tramped accidents in stadium. The main purpose of this work is to investigate the safety management level of large-scale activities by applying fuzzy synthetic assessment model, which take the measurements of risk factors or risk groups with fuzzy linguistic terms. The following section presents the step- by- step procedures to perform risk assessment of large-scale activities.

\section{Fuzzy Risk Assessment Procedure}

The procedures of fuzzy risk assessment contain two stages: preliminary stage and fuzzy risk assessment.

\subsection{Preliminary Stage}

As risk factors related to a particular large-scale activity are complex and massive, a risk assessment group must be carefully selected in order to undertake a risk assessment effectively. The members of expert group should have with different background and previous experience regarding to the large-scale activities, and a risk assessment team is usually composed of activity planner, construction designer, risk manager, etc. The task of an expert group will undertake the identification of risk sources and the measurement of risk criteria.

The risk assessment group is required to take all risk sources related to the large-scale activity under consideration. A further investigation is also undertaken to analyze the importance of each risk indicator. Risk identification is an interactive process due to the risks may evolve during the different phase of the activities. Combining the suggestions of experts, some final risk criteria are selected for the risk assessment of large-scale activities. Thus a risk assessment hierarchy is constructed.

\subsection{Fuzzy Synthetic Assessment Model}

Due to the fuzziness and uncertainty, it is difficult for experts to express the likelihood and severity of risk factors in an accurate numerical value [11]. The fuzzy set theory is considered as suitable tool for risk assessment, because it can deal with the problems relating to subjective and imprecise evaluation. In addition, the fuzzy set also allows mathematical operation with linguistic terms for decision-making [12-13]. Fuzzy synthetic assessment model is proposed for a synthetic evaluation in an uncertain environment with multiple criteria, and it is widely adopted in the field of risk assessment. For example, xianbo et. al., [14] used this method to evaluate the risk of Singapore's green projects; $\mathrm{Mu}$ et. al., [15] developed a fuzzy synthetic model to evaluate risk management level for subway project. The advantage of fuzzy synthetic assessment model lies in dealing with risk evaluation with linguistic terms and multiple criteria. In this work, a fuzzy synthetic assessment model was proposed to assess the risk level of large-scale activities. Taking Jay Chou's concert in Fuzhou as research object, the procedure of proposed fuzzy synthetic model is analyzed as follows: 
Step 1: Define risk variable and determine the membership function

The risk criteria can usually be measured by considering two risk parameters: risk probability (RP) and risk severity (RS). The risk probability represents the likelihood of each risk occurring, and the risk severity discusses the potential effect on the event. In risk assessment, the risk criticality (RC) is usually used to measure how critical result inducing by a risk factor, thus RC represents the risk level of assessment object. Due to the uncertainty and complexity, it is usually difficult to assess the risk associated with a large-scale activity. In these circumstances, the measurement of a risk criterion is suitable expressed by means of fuzzy linguistic term. According to literatures, measurement of risk probability and risk severity usually adopted five-point or seven-point scale $[13,16$, 17]. In this work, a five-point scale linguistic term is adopted for evaluation the RP and RS: $1=$ very low, $2=$ low, $3=$ middle, $4=$ high and $5=$ very high.

Step 2: calculate RP, RS and RC of risk factors

Let $i$ is the number of risk factors and $j$ is the alternative linguistic term. The membership function $R_{i}$ can be written as equation (1), in where, ${ }^{r_{i j}}$ denotes the degree to which the alternative linguistic term ${ }^{j}$ satisfied the risk factor ${ }^{i}$.

$\left(R_{i}\right)_{1 \times 5}=\left(r_{i 1}, r_{i 2}, r_{i 3}, r_{i 4}, r_{i 5}\right)$

The RP and RS of risk factor ${ }^{i}$ can be formulated as following equations:

$$
\begin{aligned}
& R P_{i}=\sum_{j=1}^{5}\left(\lambda_{j} \times r_{i j}^{R P}\right) \\
& R S_{i}=\sum_{j=1}^{5}\left(\lambda_{j} \times r_{i j}^{R S}\right)
\end{aligned}
$$

Where, ${ }^{\lambda_{j}}$ denotes the rating of risk factors, namely $\lambda_{j}=1,2,3,4,5$. In risk assessment, $\mathrm{RC}$ of a large-scale activity can be considered as the result of RP and RS. RC can be calculated as equation (4):

$R C_{i}=\sqrt{R P_{i} \times R S_{i}}$

Step 3: calculate RP, RS and RC of risk groups

In order to calculate the RP and RS of risk groups, the weight of each risk factor within each group should be determined. A simple method of weight determination is proposed according to the value of RP or RS. Assuming $n$ is the number of the risk factors within a risk group, the weights of factor ${ }^{i}$ with respect to RP and RS can be calculated by equation (5) and equation (6) respectively.

$$
\begin{gathered}
w_{i}^{R P}=R P_{i} / \sum_{i=1}^{n} R P_{i} \\
w_{i}^{R S}=R S_{i} / \sum_{i=1}^{n} R S_{i}
\end{gathered}
$$

The RP and RS membership function of risk group t can be calculated as equation (7) to equation (10) respectively: 


$$
\begin{aligned}
& r p_{t}^{G}=\sum_{i=1}^{n} w_{i}^{R P} \times r_{i j}^{R P} \\
& \left(R P_{t}^{G}\right)_{1 \times 5}=\left(w_{i}^{R P}\right)_{1 \times n} \times\left(R_{i}^{R P}\right)_{n \times 5} \\
& r s_{t}^{G}=\sum_{i=1}^{n} w_{i}^{R S} \times r_{i j}^{R S} \\
& \left(R S_{t}^{G}\right)_{1 \times 5}=\left(w_{i}^{R S}\right)_{1 \times n} \times\left(R_{i}^{R S}\right)_{n \times 5}
\end{aligned}
$$

Then, $\mathrm{RC}$ of group $\mathrm{t}$ can be calculated as equation (11):

$R C_{t}^{G}=\sqrt{R P_{t}^{G} \times R S_{t}^{G}}$

Step 4: calculate overall RP, RS and RC

In order to calculate the overall RP and RS, the weight of each risk group should be determined. The weight of each risk group was assigned according to the sum value of RP or RS. Let $q$ is the number of risk group, the weights of risk group ${ }^{t}$ with respect to $\mathrm{RP}$ and RS can be calculated by equation (12) and equation (13) respectively.

$$
\begin{aligned}
& w_{t}^{R P G}=\left(\sum_{i=1}^{n} R P_{i}\right) / \sum_{t=1}^{q}\left(\sum_{i=1}^{n} R P_{i}\right)_{t} \\
& w_{t}^{R S G}=\left(\sum_{i=1}^{n} R S_{i}\right) / \sum_{t=1}^{q}\left(\sum_{i=1}^{n} R S_{i}\right)_{t}
\end{aligned}
$$

The RP and RS membership functions of the overall risk can be formulated by following two equations.

$$
\begin{aligned}
& \left(D_{\text {all }}^{R P}\right)_{1 \times 5}=\left(w_{t}^{R P G}\right)_{1 \times q} \times\left(R_{t}^{R P G}\right)_{q \times 5} \\
& \left(D_{\text {all }}^{R S}\right)_{1 \times 5}=\left(w_{t}^{R S G}\right)_{1 \times q} \times\left(R_{t}^{R S G}\right)_{q \times 5}
\end{aligned}
$$

Based on the membership functions of the overall RP and RS, we get the overall RP and RS by equation (16) and equation (17) respectively.

$$
\begin{aligned}
& R P_{\text {all }}=\sum_{j=1}^{5}\left(\lambda_{j} \times D_{\text {all }}^{R P}\right) \\
& R S_{\text {all }}=\sum_{j=1}^{5}\left(\lambda_{j} \times D_{\text {all }}^{R S}\right)
\end{aligned}
$$

Where $\lambda_{j}=1,2,3,4,5$. Finally, the overall RC can be calculated as equation (18):

$$
R C_{\text {all }}=\sqrt{R P_{\text {all }} \times R S_{\text {all }}}
$$




\section{Case Study}

\subsection{Data Collection}

In this work, Jay Chou's concert was taken as the research object. Jay Chou's concert will be held in Fuzhou Strait Olympic sports center stadium on November 5, 2016. An expert group, consisting of 10 persons with the relevant to the safety operation of this large-scale activity, was established firstly. After discussion, the risk assessment index system of Jay Chou's concert was constructed (see Table 2). The hierarchy structure contains 4 risk groups and 14 risk factors, and the introduction of each factors are also given in Table 2.

Evaluation data concerning 4 risk groups and 14 risk factors were collected through a questionnaire, which was sent to the members of expert group. A five-point scale linguistic terms ranging from 1 to 5 was adopted, in which, $1=$ very low, $2=$ low, $3=$ middle, $4=$ high and $5=$ very high. The original data of RP and RS were obtained based on the questionnaire, as showed in Table 3. Taking "personal structure" for example, linguistic terms of RP is that very low account for $0 \%$, low $10 \%$, middle $30 \%$, high $40 \%$ and very high $20 \%$.

Table 2. Risk Assessment Index System for Large-scale Activities

\begin{tabular}{|c|c|c|}
\hline Risk group & Risk factors & Descriptions \\
\hline \multirow{3}{*}{ Human } & Personal structure (R1) & $\begin{array}{l}\text { Including the age, gender, and occupation of the } \\
\text { participants. }\end{array}$ \\
\hline & Crowd density (R2) & Reflecting the degree of congestion \\
\hline & Population status (R3) & $\begin{array}{l}\text { Representing the state of mind and mood of the crowd, } \\
\text { such as panic, anxiety and excitement. }\end{array}$ \\
\hline \multirow{4}{*}{ Infrastructure } & Building design (R4) & $\begin{array}{l}\text { The layout of the building, the quality of building } \\
\text { materials, and the number of egress. Which are directly } \\
\text { associated with the evacuation route planning. }\end{array}$ \\
\hline & Safety facilities (R5) & $\begin{array}{l}\text { Including fire control facilities, safety fence, security } \\
\text { monitoring equipment, sign of safety exit, etc. }\end{array}$ \\
\hline & $\begin{array}{l}\text { Capacity of evacuation } \\
\text { egress (R6) }\end{array}$ & $\begin{array}{l}\text { The number of evacuation egresses, the width of each } \\
\text { egress, and the other condition of evacuation egresses. }\end{array}$ \\
\hline & $\begin{array}{l}\text { Quality of Electrical } \\
\text { equipment (R7) }\end{array}$ & $\begin{array}{l}\text { The effectiveness and reliabilities of the electrical } \\
\text { equipment. }\end{array}$ \\
\hline \multirow{3}{*}{ Environment } & $\begin{array}{l}\text { Natural environment } \\
\text { (R8) }\end{array}$ & $\begin{array}{l}\text { Refers to the climate, temperature, wind speed, } \\
\text { atmospheric visibility of the natural environment. }\end{array}$ \\
\hline & $\begin{array}{l}\text { Social environment } \\
\text { (R9) }\end{array}$ & $\begin{array}{l}\text { Refers to the education culture of an individual, or an } \\
\text { organized structure created by the modes of } \\
\text { relationships between people who function in an } \\
\text { organization which in turn contributes to establishing } \\
\text { the boundaries of behavior. }\end{array}$ \\
\hline & $\begin{array}{l}\text { Surrounding } \\
\text { environment (R10) }\end{array}$ & $\begin{array}{l}\text { Refers to the road network, traffic condition, and other } \\
\text { condition of the surrounding environment. }\end{array}$ \\
\hline Management & $\begin{array}{l}\text { Safety management } \\
\text { organization (R11) }\end{array}$ & $\begin{array}{l}\text { The structure patterns of Safety management } \\
\text { organization, which affects the efficiency and accuracy } \\
\text { of safety information circulation between peoples. }\end{array}$ \\
\hline
\end{tabular}




\begin{tabular}{|c|c|}
\hline Emergency plan (R12) & The rationality and effectiveness of the emergency plan. \\
\hline & $\begin{array}{l}\text { The education for both safety technical personal and } \\
\text { participants, including the risk factors and the skills to } \\
\text { evacuation. }\end{array}$ \\
\hline $\begin{array}{l}\text { kill of safety } \\
\text { ersonnel (R14) }\end{array}$ & $\begin{array}{l}\text { The number of well-educated safety person and the } \\
\text { ability to handle emergency problems. }\end{array}$ \\
\hline
\end{tabular}

\subsection{Procedure of Fuzzy Synthetic Assessment}

Based on the original data, apply fuzzy synthetic assessment model to evaluate the risk level of Jay Chou's concert in Fuzhou. The main procedures contain three steps: calculate $\mathrm{RP}, \mathrm{RS}$ and RC of risk factors; calculate RP, RS and RC of risk groups; calculate the overall RP, RS and RC. According to the rank of RC, the risk level of risk factors, risk groups and the whole activity can be analyzed.

Step 1: calculate RP, RS and RC of risk factors

Taking "personal structure" for example, the RP and RS membership function were formulated using equation (1):

$$
\begin{aligned}
& \left(R_{1}^{R P}\right)_{1 \times 5}=\left(r_{11}^{R P}, r_{12}^{R P}, r_{13}^{R P}, r_{14}^{R P}, r_{15}^{R P}\right)=(0.00,0.10,0.30,0.40,0.20) \\
& \left(R_{1}^{R S}\right)_{1 \times 5}=\left(r_{11}^{R S}, r_{12}^{R S}, r_{13}^{R S}, r_{14}^{R S}, r_{15}^{R S}\right)=(0.20,0.30,0.40,0.10,0.00)
\end{aligned}
$$

The results of RP and RS membership functions were shown in Table 3.

Table 3. RP and RS Membership Function of Risk Factors

\begin{tabular}{cccc}
\hline Risk group & Risk factor & RP membership function & RS membership function \\
\hline \multirow{3}{*}{ Human } & R1 & $(0.00,0.10,0.30,0.40,0.20)$ & $(0.20,0.30,0.40,0.10,0.00)$ \\
& R2 & $(0.00,0.00,0.20,0.50,0.30)$ & $(0.00,0.00,0.20,0.30,0.50)$ \\
Infrastructure & R3 & $(0.30,0.40,0.20,0.10,0.00)$ & $(0.00,0.10,0.20,0.40,0.30)$ \\
& R4 & $(0.20,0.40,0.30,0.10,0.00)$ & $(0.00,0.00,0.20,0.40,0.40)$ \\
& R5 & $(0.20,0.40,0.30,0.10,0.00)$ & $(0.00,0.20,0.20,0.40,0.20)$ \\
& R6 & $(0.20,0.20,0.50,0.10,0.00)$ & $(0.00,0.00,0.30,0.40,0.30)$ \\
& R6 & $(0.30,0.50,0.20,0.00,0.00)$ & $(0.00,0.20,0.20,0.30,0.30)$ \\
Manvironment & $(0.20,0.20,0.30,0.20,0.10)$ & $(0.00,0.20,0.20,0.40,0.20)$ \\
& R9 & $(0.40,0.30,0.30,0.00,0.00)$ & $(0.30,0.20,0.40,0.10,0.00)$ \\
& R10 & $(0.00,0.10,0.50,0.30,0.10)$ & $(0.00,0.00,0.20,0.60,0.20)$ \\
& R11 & $(0.20,0.40,0.20,0.10,0.10)$ & $(0.00,0.00,0.30,0.40,0.30)$ \\
& R12 & $(0.10,0.30,0.20,0.30,0.10)$ & $(0.00,0.10,0.20,0.50,0.20)$ \\
& R13 & $(0.00,0.10,0.30,0.40,0.20)$ & $(0.00,0.00,0.20,0.50,0.30)$ \\
& R14 & $(0.10,0.20,0.40,0.20,0.10)$ & $(0.00,0.10,0.30,0.40,0.20)$ \\
\hline
\end{tabular}

Using equation (2) and equation (3), the RP and RS can be calculated respectively:

$$
\begin{aligned}
& R P_{1}=\sum_{j=1}^{5}\left(\lambda_{j} \times r_{i j}^{R P}\right)=1 \times 0.00+2 \times 0.10+3 \times 0.30+4 \times 0.40+5 \times 0.20=3.7 \\
& R S_{1}=\sum_{j=1}^{5}\left(\lambda_{j} \times r_{i j}^{R S}\right)=1 \times 0.20+2 \times 0.30+3 \times 0.40+4 \times 0.10+5 \times 0.00=2.4
\end{aligned}
$$

Then, the RC of "personal structure" was given by equation (4): 


$$
R C_{1}=\sqrt{R P_{1} \times R S_{1}}=\sqrt{3.7 \times 2.4}=2.98
$$

Similarly, RP, RS and RC of the other risk factors were obtained as shown in Table 4. From Table 4, it is evident that the top five risk factors are in the order of "Safety education (R13)", "Surrounding environment (R10)", "Crowd density (R2)", "Emergency plan (R12)" and "Skill of safety personnel (R14)", respectively.

Step 2: calculate RP, RS and RC of risk groups

In order to assess each risk group, the RP and RS weights of each risk factor within each risk group must be given firstly. Taking "human" for instance, the weight assigned to the RP and RS of "personal structure" was obtained by equation (5) and equation (6) respectively:

$$
\begin{gathered}
w_{1}^{R P}=R P_{1} / \sum_{i=1}^{n} R P_{i}=3.7 /(3.7+4.1+2.1)=0.37 \\
w_{1}^{R S}=R S_{1} / \sum_{i=1}^{n} R S_{i}=2.4 /(2.4+3.3+3.9)=0.25
\end{gathered}
$$

\begin{tabular}{|c|c|c|c|c|c|c|c|}
\hline \multirow{2}{*}{ Risk group } & \multirow{2}{*}{$\begin{array}{l}\text { Risk } \\
\text { factor }\end{array}$} & \multicolumn{2}{|c|}{$\mathrm{RP}$} & \multicolumn{2}{|c|}{ RS } & \multirow{2}{*}{$\mathrm{RC}$} & \multirow{2}{*}{ Rank } \\
\hline & & value & Group sum & value & Group sum & & \\
\hline \multirow{3}{*}{ Human } & R1 & 3.7 & 9.9 & 2.4 & 9.6 & 2.98 & 10 \\
\hline & $\mathrm{R} 2$ & 4.1 & & 3.3 & & 3.68 & 3 \\
\hline & R3 & 2.1 & & 3.9 & & 2.86 & 12 \\
\hline \multirow{4}{*}{ Infrastructure } & R4 & 2.3 & 9.0 & 4.2 & 15.5 & 3.11 & 9 \\
\hline & R5 & 2.3 & & 3.6 & & 2.88 & 11 \\
\hline & R6 & 2.5 & & 4.0 & & 3.16 & 7 \\
\hline & R7 & 1.9 & & 3.7 & & 2.65 & 13 \\
\hline \multirow{3}{*}{ Environment } & $\mathrm{R} 8$ & 2.8 & 8.1 & 3.6 & 9.9 & 3.18 & 6 \\
\hline & R9 & 1.9 & & 2.3 & & 2.10 & 14 \\
\hline & R10 & 3.4 & & 4.0 & & 3.69 & 2 \\
\hline \multirow{4}{*}{ Management } & R11 & 2.5 & 12.2 & 4.0 & 15.6 & 3.16 & 7 \\
\hline & R12 & 3.0 & & 3.8 & & 3.38 & 4 \\
\hline & R13 & 3.7 & & 4.1 & & 3.90 & 1 \\
\hline & R14 & 3.0 & & 3.7 & & 3.33 & 5 \\
\hline
\end{tabular}

Similarly, the other weights of risk factors were shown in Table 5.

Table 4. RP, RS and RC Values of Risk Factors

Table 5. Weights of RP and RS for Risk Factors and Risk Groups

\begin{tabular}{lccccc}
\hline \multirow{2}{*}{ Risk group } & $\begin{array}{c}\text { Risk } \\
\text { factor }\end{array}$ & \multicolumn{2}{c}{ RP } & \multicolumn{2}{c}{ RS } \\
\cline { 3 - 6 } Human & R1 & 0.37 & & 0.25 & \\
& R2 & 0.42 & 0.25 & 0.34 & 0.19 \\
& R3 & 0.21 & & 0.41 & \\
\multirow{3}{*}{ Infrastructure } & R4 & 0.26 & & 0.27 & \\
& R5 & 0.26 & 0.23 & 0.23 & 0.30 \\
& R6 & 0.27 & & 0.26 & \\
\hline
\end{tabular}




\begin{tabular}{lccccc}
\hline \multirow{2}{*}{ Environment } & R8 & 0.35 & & 0.36 & \\
& R9 & 0.23 & 0.21 & 0.23 & 0.20 \\
& R10 & 0.42 & & 0.41 & \\
& R11 & 0.20 & & 0.26 & 0.31 \\
& R12 & 0.25 & 0.31 & 0.24 & \\
\hline
\end{tabular}

The RP membership function of "human" group was obtained by equation (7):

$$
\begin{aligned}
r p_{1}^{G}=\sum_{i=1}^{n} w_{i}^{R P} \times r_{i j}^{R P}= & (0.37,0.42,0.21) \times\left[\begin{array}{ccccc}
0.00 & 0.10 & 0.30 & 0.40 & 0.20 \\
0.00 & 0.00 & 0.20 & 0.50 & 0.30 \\
0.30 & 0.40 & 0.20 & 0.10 & 0.00
\end{array}\right] \\
= & (0.06,0.12,0.24,0.38,0.20)
\end{aligned}
$$

Then, the RP of "human" group was calculated using equation (8):

$$
R P_{1}^{G}=\sum_{j=1}^{5}\left(\lambda_{j} \times r p_{t j}^{G}\right)=1 \times 0.06+2 \times 0.12+3 \times 0.24+4 \times 0.38+5 \times 0.20=3.54
$$
(9):

Similarly, the RS membership function of "human" group was obtained by equation

$$
\begin{aligned}
r s_{1}^{G}=\sum_{i=1}^{n} w_{i}^{R S} \times r_{i j}^{R S}= & (0.25,0.34,0.41) \times\left[\begin{array}{ccccc}
0.20 & 0.30 & 0.40 & 0.10 & 0.00 \\
0.00 & 0.00 & 0.20 & 0.30 & 0.50 \\
0.00 & 0.10 & 0.20 & 0.40 & 0.30
\end{array}\right] \\
=(0.05,0.12,0.25,0.29,0.29) &
\end{aligned}
$$

For risk groups, the results of RP and RS membership function were shown in Table 6 .

Table 6. RP, RS Membership Function of Risk Groups

\begin{tabular}{lll}
\hline Risk group & RP membership function & RS membership function \\
\hline Human & $0.06,0.12,0.24,0.38,0.20$ & $0.05,0.12,0.25,0.29,0.29$ \\
Infrastructure & $0.22,0.37,0.33,0.08,0.00$ & $0.00,0.09,0.23,0.38,0.30$ \\
Environment & $0.16,0.18,0.38,0.20,0.08$ & $0.07,0.12,0.29,0.33,0.20$ \\
Management & $0.09,0.24,0.28,0.27,0.13$ & $0.00,0.05,0.25,0.45,0.25$ \\
\hline
\end{tabular}

Then, the RS of "human" group was calculated using equation (10):

$$
R S_{1}^{G}=\sum_{j=1}^{5}\left(\lambda_{j} \times r s_{t j}^{G}\right)=1 \times 0.05+2 \times 0.12+3 \times 0.25+4 \times 0.29+5 \times 0.29=3.65
$$

Finally, the RC of "human" group was achieved by equation (11):

$$
R C_{1}^{G}=\sqrt{R P_{1}^{G} \times R S_{1}^{G}}=\sqrt{3.54 \times 3.65}=3.60
$$

In the same way, RP, RS and RC of the other group were obtained (see Table 7). 
Table 7. RP, RS and RC Values of Risk Groups

\begin{tabular}{lcccc}
\hline Risk group & RP & RS & RC & Rank \\
\hline Human & 3.54 & 3.65 & 3.60 & 2 \\
Infrastructure & 2.27 & 3.89 & 2.97 & 4 \\
Environment & 2.86 & 3.50 & 3.16 & 3 \\
Management & 3.14 & 3.90 & 3.64 & 1 \\
\hline
\end{tabular}

Step 3: calculate the overall RP, RS and RC

Using equation (12) and equation (13), the weights assigned to RP and RS of group "human" were obtained as follows.

$$
\begin{aligned}
& w_{G 1}^{R P}=\left(\sum_{i=1}^{3} R P_{i}\right) /\left(\sum_{i=1}^{14} R P_{i}\right)=9.9 / 39.2=0.25 \\
& w_{G 1}^{R S}=\left(\sum_{i=1}^{3} R S_{i}\right) /\left(\sum_{i=1}^{14} R S_{i}\right)=9.6 / 50.6=0.19
\end{aligned}
$$

Using equation (14) and equation (15), the RP and RS membership functions of the overall risk can be achieved as follows.

$$
\begin{aligned}
& D_{\text {aii }}^{R P}=(0.25,0.23,0.21,0.31) \times {\left[\begin{array}{lllll}
0.06 & 0.12 & 0.24 & 0.38 & 0.20 \\
0.22 & 0.37 & 0.33 & 0.08 & 0.00 \\
0.16 & 0.18 & 0.38 & 0.20 & 0.08 \\
0.09 & 0.24 & 0.28 & 0.27 & 0.13
\end{array}\right] } \\
&=(0.13,0.23,0.30,0.24,0.11) \\
& D_{\text {aii }}^{R S}=(0.19,0.30,0.20,0.31) \times\left[\begin{array}{lllll}
0.05 & 0.12 & 0.25 & 0.29 & 0.29 \\
0.00 & 0.09 & 0.23 & 0.38 & 0.30 \\
0.07 & 0.12 & 0.29 & 0.33 & 0.20 \\
0.00 & 0.05 & 0.25 & 0.45 & 0.25
\end{array}\right] \\
&=(0.02,0.09,0.25,0.37,0.26)
\end{aligned}
$$

With the membership functions of the overall risk, the RP and RS of overall risk can be calculated by equation (16) and equation (17):

$$
\begin{aligned}
& R P_{\text {all }}=\sum_{j=1}^{5}\left(\lambda_{j} \times D_{\text {all }}^{R P}\right)=1 \times 0.13+2 \times 0.23+3 \times 0.30+4 \times 0.24+5 \times 0.11=3.00 \\
& R S_{\text {all }}=\sum_{j=1}^{5}\left(\lambda_{j} \times D_{\text {all }}^{R S}\right)=1 \times 0.02+2 \times 0.09+3 \times 0.25+4 \times 0.37+5 \times 0.26=3.73
\end{aligned}
$$

Finally, the overall RC of the activity was achieved by equation (18):

$$
R C_{\text {all }}=\sqrt{R P_{\text {all }} \times R S_{\text {all }}}=\sqrt{3.00 \times 3.73}=3.35
$$

Because the whole risk criticality is 3.35 , which is closest to the fuzzy linguistic term "middle". Thus, the overall risk criticality of Jay Chou's concert in Fuzhou was considered as middle. 


\section{Results and Discussions}

Assessment index system of the safety operation for Jay Chou's concert in Fuzhou was constructed as shown in Table 1 , and the preliminary data of risk factors were obtained from 10 experts associated with the safety operation of Jay Chou's concert, as showed in Table 2. A fuzzy synthetic assessment model was used to evaluate the safety level of the activity, and the analysis results were summarized as follows.

The evaluation values of risk groups were in order of "management", "human", "environment" and "infrastructure". The results indicate that the top two risk groups are associated with human, which in accord with the results of most literatures. In other words, accidents are most likely caused by human related factors [13, 21]. The lowest risk group is "infrastructure", because of Fuzhou Strait Olympic sports center stadium is a new stadium with high designed standard.

The top five risk factors are in the order of "Safety education (R13)", "Surrounding environment (R10)", "Crowd density (R2)", "Emergency plan (R12)" and "Skill of safety personnel (R14)", respectively. It is worth noting that three are three factors deriving form the "management" group. The results indicate that the stampede accidents are most likely caused by human related factors. As a consequence, implementing safety education, improving safety operation skill, and perfecting emergency plan are three import issues associated with human factors to reduce the probability and severity of a stampede accident. Simultaneously, we must put enough attention to "Surrounding environment (R10)" and "Crowd density (R2)". The effective traffic management of surrounding road network and the limitation of participants also were the important issues to the safety operation of Jay Chou's concert.

\section{Conclusions}

There are many factors that influence the safety operations of a large-scale activity in a public place, and an assessment of these risk factors in terms of their impacts on the safety operations of large-scale activities involves imprecise information with subjective judgment. Therefore, a fuzzy synthetic model with fuzzy linguistic terms was proposed to evaluate the safety level of Jay Chou's concert in Fuzhou. A hierarchy structure of assessment index system was constructed with 14 factors in 4 groups, and the evaluation values of each risk factor with fuzzy linguistic terms were obtained from the experts. The procedures of fuzzy synthetic assessment model were presented step by step. The results reveal that the top five factors are "Safety education (R13)", "Surrounding environment (R10)", "Crowd density (R2)" "Emergency plan (R12)" and "Skill of safety personnel (R14)", and the top risk group is "management". The reasons and the some suggestions are also given with regarding to the results of fuzzy risk analysis, which should be provided a basis for the safety management organization to prevent the stampede accidents.

\section{Acknowledgements}

This work was supported by the Natural Science Foundation of Fujian Provincial under Grant No. 2016J01757, the Scientific Research Project of Young Teachers in Fujian Province under Grant No. JA14256 and the Science and Technology Program of Minjiang University under Grant No. MYK15008. 


\section{References}

[1] L. Menglong, P. Hongjian, Z. Xinkang and D. Luoping, "Research on risk assessment system of mass crowded stampede-trampling accidents in stadium", Applied Mathematics \& Information Sciences, vol. 6 , no. $1,(\mathbf{2 0 1 2})$.

[2] Henein, Coin M. White, Tony, "Macroscopic effects of microscopic forces between agents in crowd model”, Physica A Statistical Mechanics and Its Application, vol. 373, no. 36, (2007).

[3] Z. Li-mao, L. Meng-jie, W. Xian-guo and Z. Jing-bing, "Risk analysis of crowed stampede accident in subway stations based on DEA method", Journal of Civil Engineering and Management, vol. 31, no. 4, (2014).

[4] H. Singh, R. Arter, L. Dodd, P. Langston, E. Lester and J. Drury, "Modelling subgroup behavior in crowd dynamics DEM simulation", Applied Mathematical Modelling, vol. 33, no. 12, (2009).

[5] S. Mukherjee, D. Goswami and S. Chatterjee, "A lagrangian approach to modeling and analysis of a crowd dynamics", IEEE Transactions on Systems, Man and Cybernetics, vol. 45, no. 6, (2015).

[6] N. Bellomo, A. Bellouquid and D. Knopoff, "From the microscale to collective crowd dynamics", Multiscale Modeling \& Simulation, vol. 11, no. 3, (2013).

[7] L. Jianfeng, L. Mao and S. xiaolin, "The comprehensive measurement of the influence of accident type factor on people gathering risk", Journal of Safety and Environment, vol. 7, no. 5, (2007).

[8] Z. Qing-song, L. Mao and Z. Guo-min, "Study on stranded crowd number quantitative model of stadium crowd evacuation", Journal of Safety and Environment, vol. 6, no. 3, (2006).

[9] L. Yan, W. Tong, D. Hui and W. zongzhi, "Research and application on risk assessment DEA model of crowd crushing and trampling accidents in subway stations", Procedia Engineering, vol. 43, (2012).

[10] Z. Jiao and C. Gan, "Risk assessment of crowd crushing and tramping accident in urban rail transit station based on DEA", Applied Mechanics and Materials, vol. 730, (2014).

[11] Shan M., Chan A. P., Le Y., Xia B. and Hu Y., "Measuring corruption in public construction at the project in china", Journal of Professional Issues in Engineering Education and Practice, vol. 141, no. 4, (2015).

[12] J. Zeng, M. An and N. J. Smith, "Application of a fuzzy based decision making methodology to construction project risk assessment", International Journal of Project Management, vol. 25, (2007).

[13] J.-f. Ding and W.-j. Tseng, "Fuzzy risk assessment on safety operations for exclusive container terminal at Kaohsiung port in Taiwan", Journal of Engineering for the Maritime Environment, vol. 227, no. 2, (2013).

[14] X. Zhao, B.-G. Hwang and Y. Gao, "A fuzzy synthetic evaluation approach for risk assessment: a case of Singapore's green projects", Journal of Cleaner Production, vol. 115, (2016).

[15] Mu S., Cheng H., Chohr M. and Peng W., "Assessing risk management capability of contractors in subway projects in mainland China”, International Journal of Project Management, vol. 32, no. 3, (2014).

[16] W.-J. Tseng, J.-F. Ding, C.-C. Chou and M.-T. Lin, "Transport risks analysis of temperature-controlled cargoes for airfreight forwarders in Taiwan: case study of the orchids", African Journal of Agricultural Research, vol. 6, no. 27, (2011).

[17] H. Ni, A. Chen and N. Chen, "Some extensions on risk matrix approach", Safety Science, vol. 48, no. $10,(2010)$.

[18] L. Ze-zhao, Y. Fan and H. Jie, "On fussy risk assessment for stampede accident in large public eventsanalysis of shanghai "12.31" stampede incidence", Journal of Nanjing University of Aeronautics and Astronautics (Social Sciences), vol. 17, no. 2, (2015).

[19] Q. Lai-ming, "Risk assessment system of stampede accidents in sports stadiums", Journal of Wuhan Institute of Physical Education, vol. 45, no. 11, (2011).

[20] W. Qiquan and J. Longzhe, "Analysis of GAHP in crowded stampede accidents of large-scale activities", Journal of Liaoning Technical University (Social Science Edition), vol. 10, no. 5, (2008)

[21] C.-S. Lu and K.-c. Shang, "An empirical investigation of safety climate in container terminal operators", Journal of Safety Research, vol. 36, no. 3, (2005).

\section{Authors}

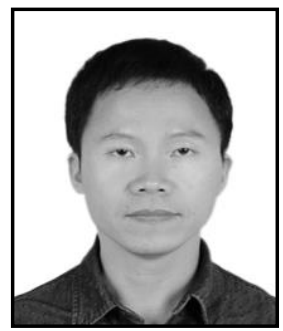

Zheng Jianhu, He received his $\mathrm{Ph}$. D. degree from the Department of Transportation Engineering, Tongji University, China, in 2007. Since 2009, he is a vice professor with the School of Economics and Management, Minjiang University, China. His research interests include intelligent transportation system, urban planning and traffic safety. 


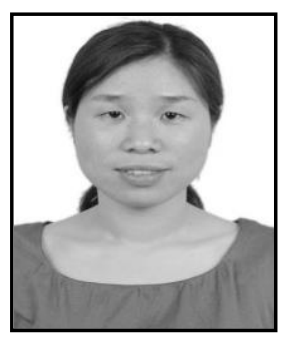

Huang Mingfang, She received her M.S degree from Fujian Agriculture and Forestry University, China, in 2007. Her main research interests include traffic safety and system engineering. 